\title{
A Proposed Scheme for Fault Discovery and Extraction Using ANFIS: Application to Train Braking System
}

\author{
Tse Sparthan ${ }^{1}$, Wolfgang Nzie ${ }^{1}$, Bertin Sohfotsing ${ }^{2}$, Olivier Garro ${ }^{1}$, Tibi Beda ${ }^{1}$ \\ ${ }^{1}$ National Advance School of Agro-Industrial, University of Ngaoundere, Ngaoundere, Cameroon. \\ ${ }^{2}$ University Institut of Technology, University of Dschang, Dschang, Cameroon. \\ Correspondence: Tse Sparthan, National Advance School of Agro-Industrial Science, University of Ngaoundere, \\ Ngaoundere, Cameroon. \& The College of Technology, University of Bamenda, Cameroon.
}

Received: April 22, 2020 Accepted: July 16, 2020 Online Published: July 20, 2020

doi:10.11114/set.v7i1.4822

URL: https://doi.org/10.11114/set.v7i1.4822

\begin{abstract}
This paper showcases the use of model oriented techniques for real time fault discovery and extraction on train track unit. An analytical system model is constructed and simulated in Mathlab to showcase the fair and unfair status of the system. The discovery and extraction phases are centered on a hybrid adaptive neuro-fuzzy inference feature extraction and segregated module. Output module interprites zero (0) as a good status of the traintrack unit and one (1) as an unpleasant status. Final results showcase the robustness and ability to discover and extract multitude of unpleasant scenarios that hinder the smooth operations of train track units due to its high selectivity and sensitivity quality.
\end{abstract}

Keywords: fault discovery and extraction (FDE), ANFIS (Artificial Neauro Fuzzy Inference System), Artificial intelligence (AI), traintrack system

\section{Introduction}

To effectively stabilize railway transportation sector, the actors must strongly rely on the quality of the train track components. Because their design outstands significant numbers of operations which becomes complex to manage with human intelligence. The assistance for an AI technique is strongly requested. This has led to plenty of engineering and scientific solutions. In a global view point, diagnostics help to discover and extract fault scenarios on systems in respect of their size (Lee et al, 2014), which is an inevitable aspect of maintenance management. Fault discovery and extraction is centered on residual signals gain when an unpleasant status of a given system is identified based on the input and output module. In practice, the train track system has a nonlinear attitude and thus strictly rely on sophisicated AI entities (Vasile et al., 2002), which intergrates soft computing concepts such as fuzzy logic, neural network, genetic algorithm and hybrid (eg: neuro-fuzzy) techniques.

Neural networks have been applied to fault discover and extraction problems, due to their abilities to intergrates non linearity, complexity, uncertainty, noisy, self-learning and adaptation, but lacks transparency in human interpretation due to its black box nature (Marcus et al., 2000). Fuzzy logic is favorable as decisions taken for fault extraction is done within human capacity and understanding. Excess timing is requested and thus less precise results are compared to other techniques (Jie et al., 2016). For improvements, neural network and fuzzy logic called neuro-fuzzy or fuzzy-neuro hybrid systems are blind. It is the ability of rule base designs, automatic linguistic modeling, application to nonlinear systems, strong learning abilities, parallel processing and fault-tolerance abilities since it is a framework that brings together both numerical and symbolic knowledge of the process equipments (Muhammad, 2017; Xiaomeng, 2019). TSK named after (Takagi Sugeno and Kang) and Mamdani models are two types adapted to our activities. ANFIS's is a hybrid discovery and extraction computing system that improve an intergrated fuzzy set through artificial neural network algorithm (Lee et al., 2014). In practice, neuro-fuzzy models are establised base on system requirement such as transparency, processing speed, complexity, adaptive learning and transformability. The ANFIS valorize involve the antecedent and conclusive sections inter connected together in five layers with the following job description (figure 1) (Hadroug et al., 2016). Layer 1 serves as an input fuzzifier unit, layer 2 is a fuzzy unit for "if then" activities, layer 3 serves as the unit for membership normalization job, layer 4 the conclusive units for "if then" activities and finally the output computational job is realised in layer 5 . 


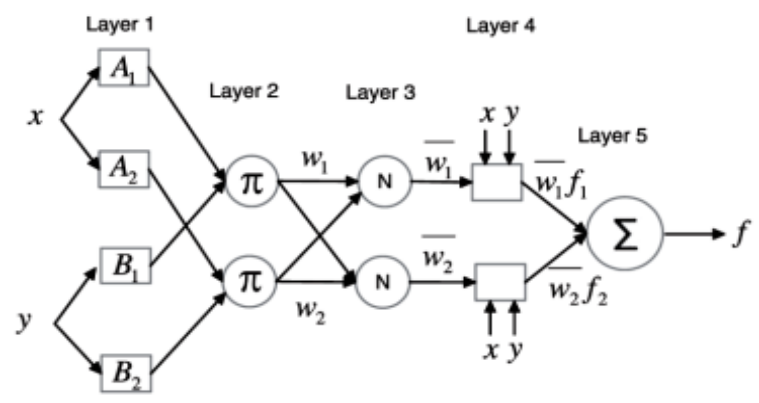

Figure 1. Architecture of the TSK model adopted (Hadroug et al., 2016)

This summary aims at blinding neuro-fuzzy and system models to establish fault discovery and extraction perfectly on train track unit. Unpleasant scenarios always affects the safe transportation of passengers and freights, and as such drop in productivity. So in order to guarantee safety, a good maintenance strategy centers on failure discovery and extraction using neural network, fuzzy logic, Clonal Selection Classification Algorithm and support vector machine framework has been presented (Demetgul et al., 2009; Shahab \& Moavenian, 2012; Jegadeeshwaran \& Sugumaran, 2015; He et al., 2017), but limited on individual components of the system. Meaning they do not take in consideration the interactive aspect in between the main components of the system, inconsistency of results, even though fuzzy logic systems present quality ability for human interpritation problems. For consistency, we blind the option of ANFIS's to establish a discovery and extraction module in section two. A proposed scheme and its application in section three and four, while discussion and conclusion are initiated in section five so as to improve on the status of condition based maintenance in the rolling stuck industries.

\section{Method}

\subsection{The Proposed Hybrid System}

During the design phase of engineering systems, physics law are used to establish the behavioral aspect of single or assembly of parts according to their different movement. In this light, one can guarantee that the average attitude of traintrack systems are known early enough. Meaning that to follow up their healthy state, engineers and scientist should initiate tools and methodologies which will focus from the design stage (proactive) right up to its usage (active) before fall out. Even though many have heavily focused on after failure discovery data sets generated from field work, the presence of impurities in most cases weakens the quality of the data collected and as such push them to use analytical models. If during design we define the healthy state using the physics laws of each system components, then a fault diagnoser is established as depicted in figure 2. The diagnoser uses five different modules to outperform failure discovery and extraction actions.

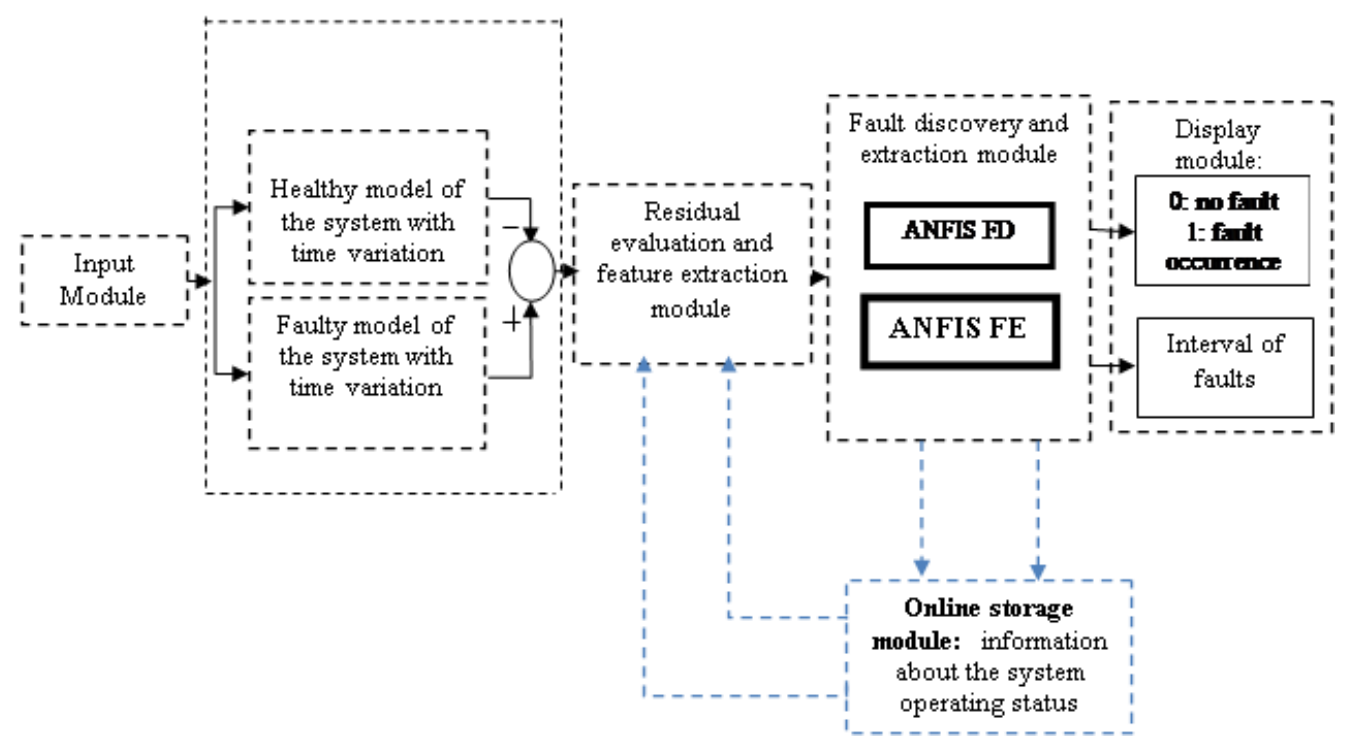

Figure 2. An automatic hybrid model for FDE

The Input Module brings forward all the parameters or signals defined by the constructor (threshold) during the design phase of the traintrack system intergrated in the technical hand book.

Fair and Unfair module are later constructed using analytical models that explain the legit behavioral function of the 
system in the presence of uncertainties. For proactive situations, the manufacturers must provide an input threshold signal or information about the smooth operation of the individual components. These threshold signals which define the quality of the system during operations is then used by the initiated diagnoser to derivate at every given instant the unfair state from the fairly state.

Data Acquisition and Feature Extraction Module constitute two post processing actions, which make it different, and complex from previous works found in the review. In the first case, a feature extraction activity relies on the unlike measured variables and their approximate called residual signal which carries reliable information necessary for a successful failure discovery and segregation. The second case depends on signals gained after a given period of operating our system. The operational historical data acquired within a certain period stored in the online storage module are sent back to the feature extraction module. Before then, all unfair data must be distinguished from fairly ones. New residual signals are gained based on the comparism between the original signal that defines the good state of the system obtained from analytical models using system parameters and the new historical signals. The construction of this module eliminates the notion of loss or lack of sufficient data to carry out fault discovery and extraction phase on train track units. Because it has an auto verification ability the output of this module is linked to the various ANFIS's detector or extractors 1 and the display module denoted 2 for model validation (figure 3 ).

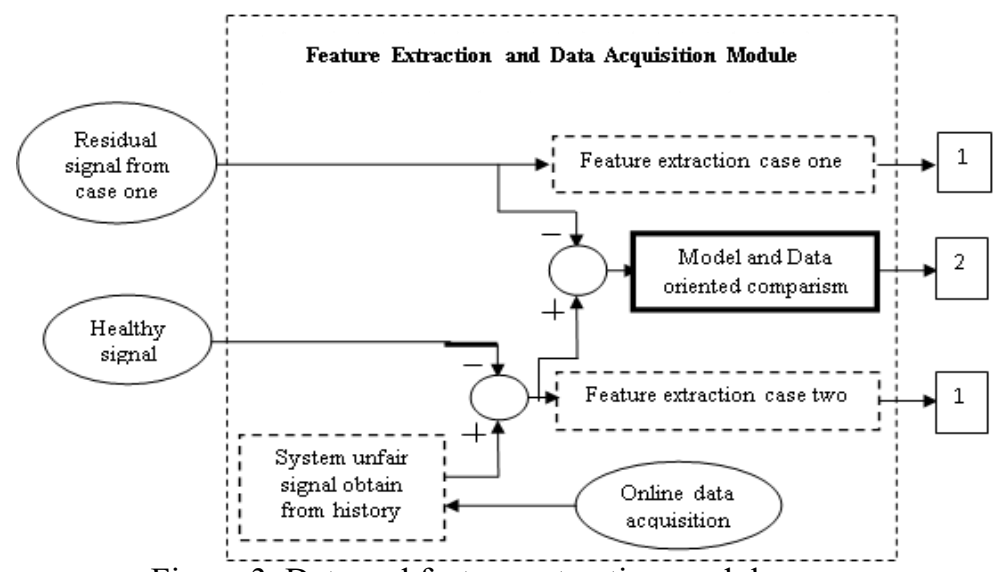

Figure 3. Data and feature extraction module

Fault Discovery and Extraction Module extract and classify the different unfair from fair situations using ANFIS since it has the ability to manage non linearity issues in real time. The first ANFIS is established for fault discovery actions and a second ANFIS for fault arrangement actions.

Display Module serves as a screen where all the output of the different healthy and unhealthy scenarios with their

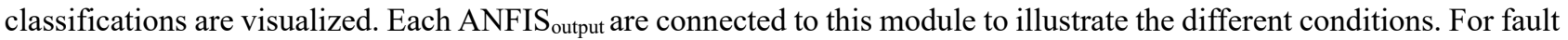
discovery issues, the output shall indicate zero conditions for healthy status and one for unhealthy status

Online Storage Module: ANFIS ${ }_{\text {output }}$ are collected on regular bases in the form of data. This real time data that illustrates the status of the system is directly used as input signal to the data acquisition and feature extraction module after the system must have works for a given period. The aim here is to verify the quality of the diagnostic tool through comparism of the model oriented and the signal oriented methods.

\subsection{Demonstration of the automatic FDE}

In order to valorize the automatic FDE system, the rail vehicle braking system for a Locomotive CC2200 with leaks between main components is considered (figure 4). During operation, air is compressed and stored at about 8 bar, the EPV mounted on each of the rail vehicle are energized with current. The control pressure of each EPV will adjust the control pressure of each RV (Relay valve). The RV downstream pressure $\left(P_{r v, d s}\right)$ is maintained at the input control pressure delivered to the brake chamber. The pressure in the brake chamber will influence the piston assemble and brake pad to contact the wheel for effective slow down or complete train stop (Adel et al., 2009; Lionel \& Chen, 2011). Table 1 below identifies the key units. It should be noted that the rubber balance spring stiffness is not a specific value, but a variable and the reset spring elasticity coefficient $\mathrm{k}_{1}$ and relies on the return spring displacement.

\subsubsection{Fault Free State}

The equation of motion expressing the moving attitude of the piston and pressure behavior across key units of the braking system (Shankar, 2006) 
Table 1. Characteristics of the main components for the Locomotive CC2600 train pneumatic braking system (Lu et al., 2015; Tse et al., 2014; Boseong et al., 2016)

\begin{tabular}{|c|c|c|c|c|c|c|c|}
\hline Ref & Parameter & SI unit & Valve & $\begin{array}{c}\text { Ref } \\
\text {. }\end{array}$ & Parameter & $\begin{array}{c}\text { SI } \\
\text { unit }\end{array}$ & Valve \\
\hline \multirow{13}{*}{ 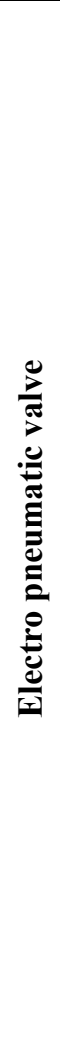 } & $\begin{array}{l}\text { Rubber balance } \quad \text { spring } \\
\text { stiffness }\end{array}$ & $\mathrm{N} \cdot \mathrm{mm}^{-1}$ & Data* & \multirow{8}{*}{ 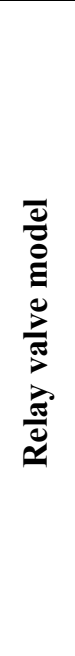 } & Control piston diameter & $\mathrm{mm}$ & 84.36 \\
\hline & Upper cavity piston diameter & $\mathrm{mm}$ & 56.45 & & $\begin{array}{l}\text { Piston reduced pressure rod } \\
\text { diameter }\end{array}$ & $\mathrm{mm}$ & 21.00 \\
\hline & Push rod diameter of piston & $\mathrm{mm}$ & 22.80 & & $\begin{array}{l}\text { Outlet valve hole inner } \\
\text { diameter }\end{array}$ & $\mathrm{mm}$ & 15.23 \\
\hline & Piston return spring stiffness & $\mathrm{N} \cdot \mathrm{mm}^{-1}$ & 1.63 & & $\begin{array}{l}\text { Outlet valve hole outer } \\
\text { diameter }\end{array}$ & $\mathrm{mm}$ & 25.70 \\
\hline & Spring pre pressure & $\mathbf{N}$ & 48.20 & & Inlet valve hole outer diameter & $\mathrm{mm}$ & 33.40 \\
\hline & Lower cavity piston diameter & $\mathrm{mm}$ & 69.62 & & Inlet valve hole inner diameter & $\mathrm{mm}$ & 23.90 \\
\hline & Push rod diameter of piston & $\mathrm{mm}$ & 19.64 & & Spring pre-pressure & $\mathrm{N}$ & 21.32 \\
\hline & Valve outer diameter & $\mathrm{mm}$ & 31.00 & & Spring elasticity coefficient & $\begin{array}{c}\mathrm{N} \cdot \mathrm{m} \\
\mathrm{m}^{-1}\end{array}$ & 1.32 \\
\hline & Valve inner diameter & $\mathrm{mm}$ & 25.00 & \multirow{5}{*}{ 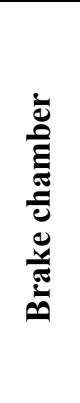 } & Control piston diameter & $\mathrm{mm}$ & 84.36 \\
\hline & Valve hole diameter & $\mathrm{mm}$ & 20.00 & & $\begin{array}{l}\text { Piston reduced pressure rod } \\
\text { diameter }\end{array}$ & $\mathrm{mm}$ & 21.00 \\
\hline & $\begin{array}{l}\text { Valve spring elasticity } \\
\text { coefficient }\end{array}$ & $\mathrm{N} \cdot \mathrm{mm}^{-1}$ & 3.29 & & $\begin{array}{l}\text { Outlet valve hole inner } \\
\text { diameter }\end{array}$ & $\mathrm{mm}$ & 15.23 \\
\hline & $\begin{array}{l}\text { Valve core return spring } \\
\text { pre-pressure }\end{array}$ & $\mathbf{N}$ & 55.93 & & $\begin{array}{l}\text { Outlet valve hole outer } \\
\text { diameter }\end{array}$ & $\mathrm{mm}$ & 25.70 \\
\hline & current & $\mathrm{mA}$ & 1000 & & & & \\
\hline
\end{tabular}




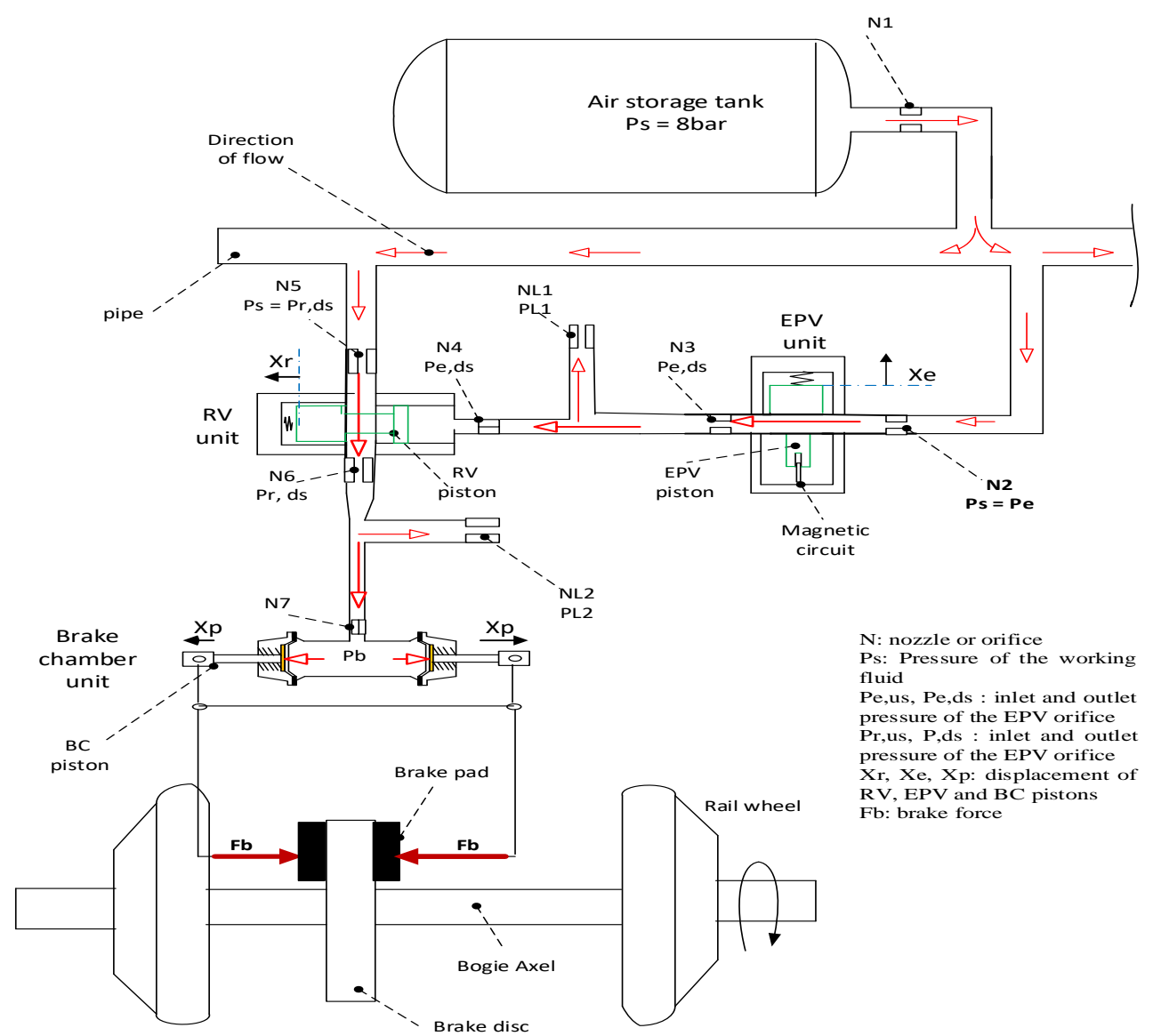

Figure 4. Model for train pneumatic braking system

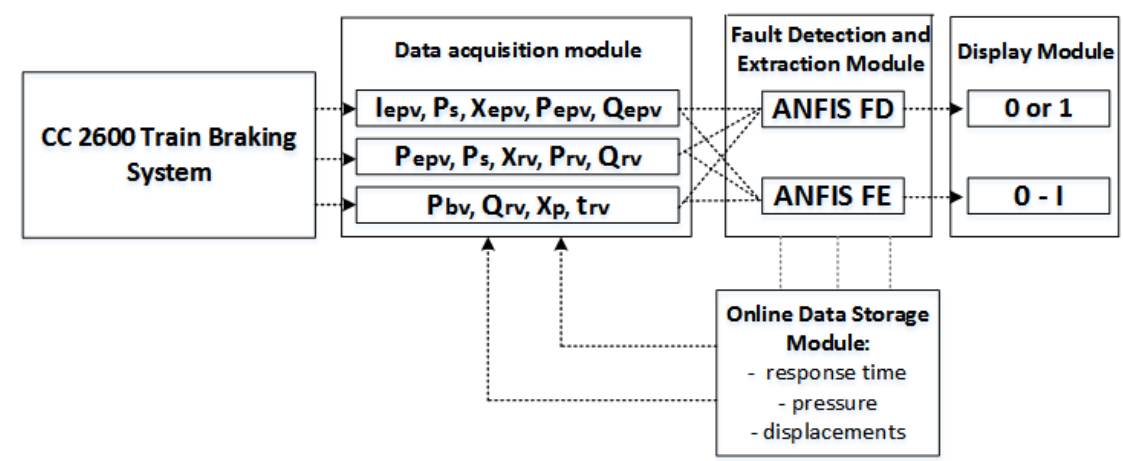

Figure 5. CC 2600 Locomotive braking system failure discovery and extraction process using ANFIS

\section{Electropnuematic Valve (EPV):}

Equation (1) below is a thermo fluid expression across the EPV with $P_{e p v, d s}, P_{e p v, u s}, P_{r v, d s}$ and $P_{r v, u s}$ supply and out pressure of the EPV and RV respectively, $M_{e p v}, M_{r v}, M_{r v}, \dot{Q}_{i}$ respective piston masses and flow rate, $\theta_{i}$ the temperature, $R$ gas constant, $\mathrm{C}_{\mathrm{D}}$ discharge coefficient, $\beta$ specific heat, $\gamma$ ratio of specific heat and $r_{i}$ external radius of the relay valve. $M_{1}$ and $M_{2}$ constant. $x_{e p v}, x_{r v}$ and $x_{p}$ are displacements of the EPV, RV and BC respectively and $x_{a b}$ distance to be considered. $C_{e p v}, p_{i e p v} w$ and $h$ Spring stiffness, dumping, presuure width and height inside the EPV respectively. $A_{e}$ the flow cross sectional area of the nozzle.

$$
\left\{\begin{array}{c}
M_{e p v} \frac{d^{2} x_{e p v}(t)}{d t^{2}}=F_{e p v}(t) i_{e}(t)-C_{e p v} \frac{d x_{e p v}}{d t}-K_{e p v} x_{e p v}(t)-\frac{\omega h}{2} p_{i e p v} \\
F_{e p v}(t)=\frac{d}{d t}\left[\frac{1}{2}\left(L_{e} i_{e}(t)^{2}\right)\right]
\end{array}\right.
$$




$$
\left\{\begin{array}{c}
\frac{d P_{e p v, u s}}{d t}=\frac{A_{e p v} C_{q} C_{r}}{Q_{e p v, a} \sqrt{\theta_{e p v, u s}}} \\
C_{Q}=0.8414-0.1002\left(\frac{P_{e p v, d s}}{P_{e p v, u s}}\right)+0.8415\left(\frac{P_{e p v, d s}}{P_{e p v, u s}}\right)^{2}-3.9\left(\frac{P_{e p v, d s}}{P_{e p v, u s}}\right)^{3}+ \\
4.6001\left(\frac{P_{e p v, d s}}{P_{e p v, u s}}\right)^{4}-1.6827\left(\frac{P_{e p v, d s}}{P_{e p v, u s}}\right)^{5}
\end{array}\right.
$$

In practice if the pressure ratio below critical $P_{c r}$, the mass flow shall rely on the pressure and the flow parameter across the EPV due to tubular effect which affects the pressure ratio.

$$
C_{r}\left\{\begin{array}{c}
\sqrt{\frac{\gamma}{\gamma-1} \frac{2}{R}} * \sqrt{\left(\frac{P_{e p v, d s}}{P_{e p v, u s}}\right)^{2}-\left(\frac{P_{e p v, d s}}{P_{e p v, u s}}\right)^{\frac{\gamma+1}{\gamma}}}, \text { if }\left(\frac{P_{e p v, d s}}{P_{e p v, u s}}\right)>P_{c r} \\
\sqrt{\frac{\gamma}{\gamma-1} \frac{2}{R}} *\left(\frac{2}{\gamma+1}\right)^{\frac{1}{\gamma-1}} \quad, \text { if }\left(\frac{P_{e, d s}}{P_{e, u s}}\right) \leq P_{c r} \\
P_{c r}=\left(\frac{2}{\gamma+1}\right)^{\frac{1}{\gamma-1}}=0.528
\end{array}\right.
$$

\section{Relay valve (RV):}

Equation (4\&5) demonstrates the mechanical actions of the RV with $F_{r v, k}, S_{r v, i}, S_{r v 1,2}$ and $S_{r v}$ spring, preload, piston and gasket area exposed to pressurized air (inlet and out let ports), full area at the delivery port of the RV.

- Applied and hold phase

$$
K_{r, g} x_{a}(t)-P_{e, d s}(t) S_{r, a}-K_{r v, g} x_{r v}(t)+P_{r v, d s}(t)\left(S_{r, a 1}-S_{r 2}\right)+P_{r v, u s} S_{r 1}+F_{r, k}+P_{a t m} S_{r v}=0
$$

Release phase

$$
P_{e, d s}(t) S_{r, a}=-P_{r, r d}(t)\left(S_{r, a 1}+S_{r 2}\right)
$$

\section{Brake Chamber:}

Equation (6\&7) are characteristic demonstration of the mass flow and pressure response of the $\mathrm{BC}$ where $V_{b c}, V_{b c 1,2}, S_{b c}, K_{b c}$ and $F_{k b i}$ are the initial volume of air, maximum volume of air, area, spring stiffness and preload. $R$ gas constant, $\mathrm{C}_{\mathrm{D}}$ discharge coefficient, $\beta$ specific heat, $\gamma$ ratio of specific heat and $r_{i}$ external radius of the relay valve or brake chamber inlet section $M_{1}=1.419 * 10^{-6} \mathrm{~m} / \mathrm{Pa}$ and $M_{2}=2.341 * 10^{-6} \mathrm{~m} / \mathrm{Pa}$ are constant obtained from experimental calibration in (Srivatsan, 2008)

$$
\begin{aligned}
& M_{b c}\left(\frac{d^{2} x_{p}(t)}{d(t)^{2}}\right)=\left(P_{r v, r d}(t)-P_{a t m}\right) S_{b}-K_{p} x_{p}(t)-F_{k b c}
\end{aligned}
$$

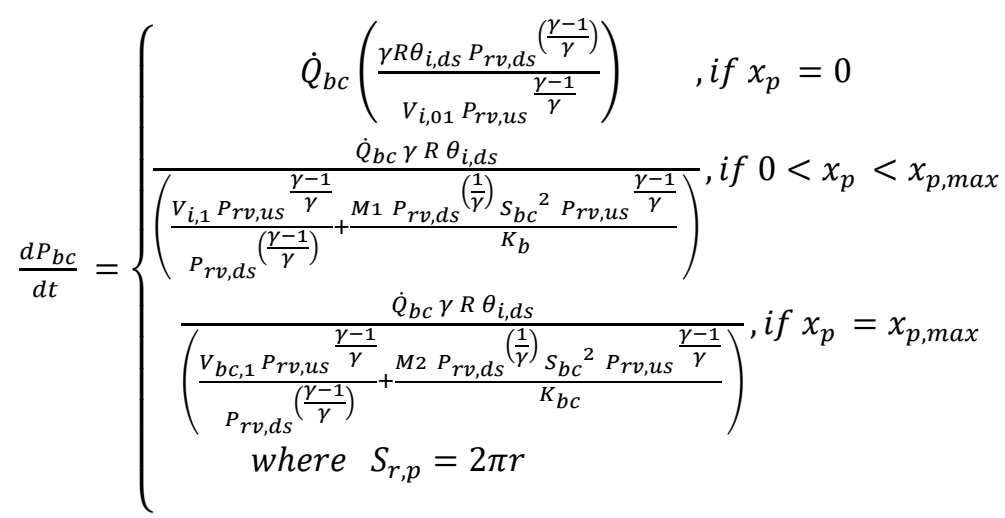

\subsubsection{Faulty State}

Leaks are assume between key units as a nozzle. Their governing equation (equation 8-10): Where $\dot{Q}_{l 1}$ and $\dot{Q}_{l 2}$ is the mass flow rate of compressed air leaked out to the atmosphere when the brake is applied. Practically, $\dot{Q}_{l 1}$ and $\dot{Q}_{l 2}$ increases as the supply pressure $P_{s}$ and the leak effective area do increase equation (9). $P_{S}=P_{i v, u s}$ supply pressure, $\dot{Q}_{L i}$ is the leak flow rate, $\theta_{i}$ the temperature at point $\mathrm{i}^{\text {th }}$ on the rail vehicle brake system and $C_{d L i}=C_{D}$ discharge coefficient because the fluid is homogenous. In reality, $S_{L}$ is very difficult to obtain theoritically, can only be measured practically. The leak effective area is adopted from Srivatsan, 2008. 


$$
\begin{gathered}
\left\{\begin{array}{l}
\dot{Q}_{e, d s}=\dot{Q}_{l 1}+\dot{Q}_{r b} \\
\dot{Q}_{r, d s}=\dot{Q}_{l 2}+\dot{Q}_{b}
\end{array}\right. \\
\dot{Q}_{L i}=g\left(P_{s}, S_{L i}\right) \\
\dot{Q}_{L i}=S_{L i} C_{d L i} \frac{P_{s}}{\sqrt{R \theta_{i}}} \sqrt{\left(\frac{2}{\gamma+1}\right)^{\frac{\gamma+1}{\gamma-1}}} \\
S_{L i} C_{d L i}=-2.4945 P_{s}+229.34 \\
\dot{Q}_{L i}=\left(-2.4945 P_{s}+229.34\right) \frac{P_{s}}{\sqrt{R \theta_{i}}} \sqrt{\left(\frac{2}{\gamma+1}\right)^{\frac{\gamma+1}{\gamma-1}}}
\end{gathered}
$$

\subsubsection{Data Development}

The effectiveness of any fault discovery and extracting unit rely on the quality of it input data. Due to inconsistency of field recording data, the above equations (1-12) are combined and resolved in Mathlab using ODE45 resolution techniques. Being a nonlinear system, fair and unfair data are developed taking in to account the presences of leaks between the Electropneumatic valve - relay valve, relay valve - brake chamber and no contact between the brake shoe and disc. Appendix depicts the step by step data development using Mathlab computer tool with figure (8\&11) showcasing the manifestation of the different fault scenarios as piston displace acceleration evolves. The manner with which field data's are established, trained and tested using ANFIS is showcased in figure 5 above.

\section{Results}

The good attitude of any protective system in a Locomotive CC2600 is center on quick response and rescission time when called to practice. Meaning for effective monitoring of the train braking operations, an appropriate fault discovery and extraction tool should be designed and centered on time reactions of its main components. Figure 6-8 displays the attitude of the key control units of the train braking system and how the output velocity of the piston (EPV) is immediately influence as pressure drop within them is concerned at $\dot{Q}_{l 2}$ and $\dot{Q}_{l 1}$. The brake response time during the applied, hold and exhaust phase should be within 0.6s and 0.8s (Lu et al., 2015).

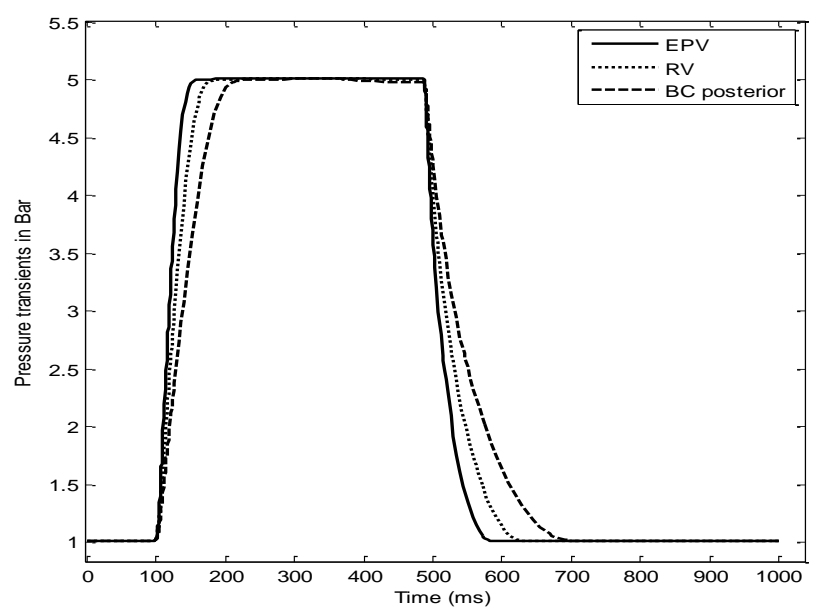

Figure 6. Attitude of the main braking units without leaks $(\mathrm{Ps}=5 \mathrm{bar})$

From a computing point, the good attitude of the EPV, RV and BC, guarantee the fast and stable output of an automobile braking operation as depicted in table 2 . Table 3 view the output coordinating time of the key braking units with or without the presence of leaks $\dot{Q}_{l 1}$ and $\dot{Q}_{l 2}$. 

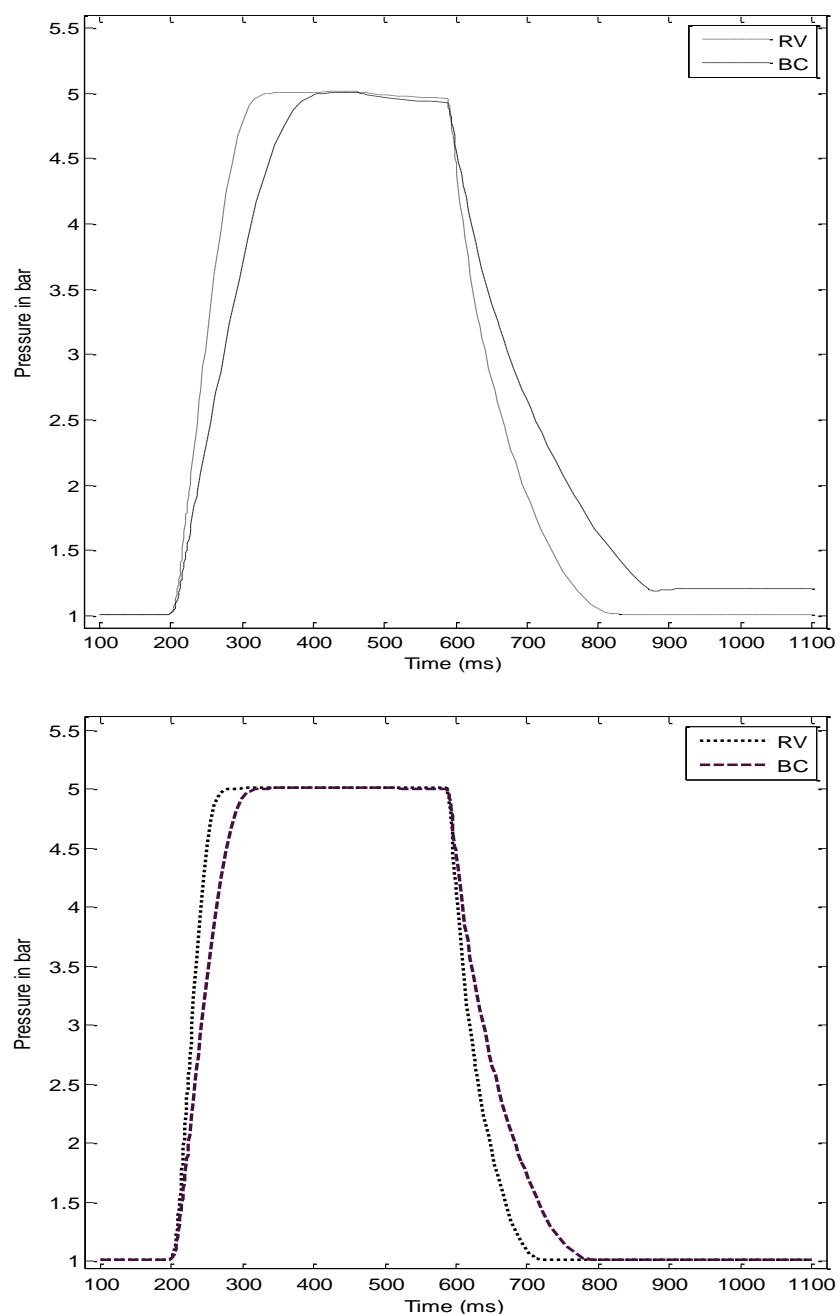

Figure 7. Attitude of the main braking units with leaks $\dot{q}_{l 1}$ and $\dot{q}_{l 2}(\mathrm{Ps}=5 \mathrm{bar})$

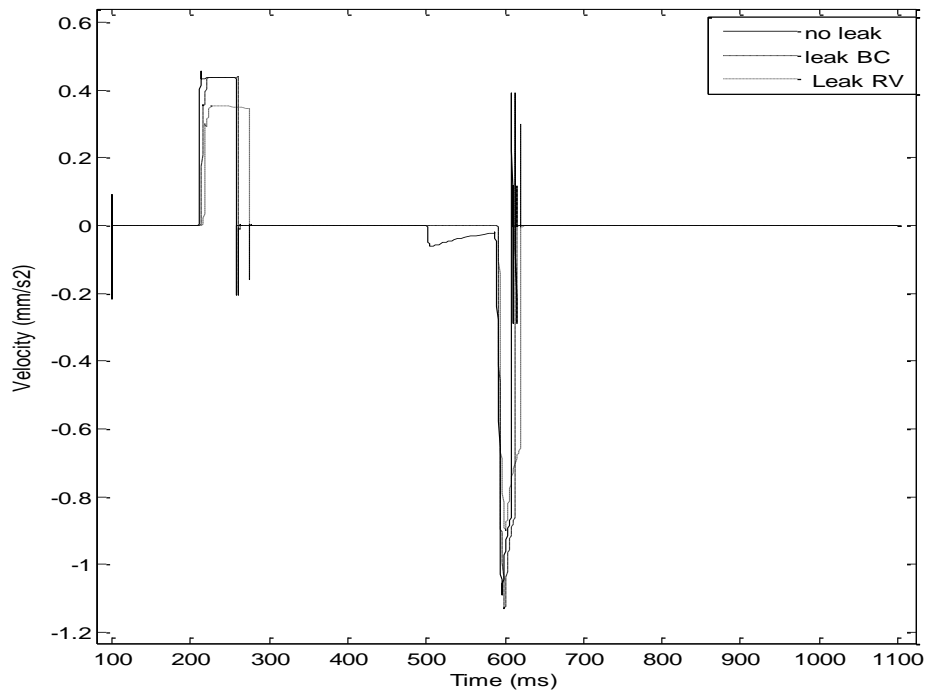

Figure 8. Effect of leak on Piston position $\left(\mathrm{P}_{\mathrm{s}}=5 \mathrm{bar}\right)$ 
Table 2. Output dynamic response time

\begin{tabular}{l|c|c}
\hline \multirow{2}{*}{ System state } & \multicolumn{2}{|c}{ Dynamic response time (ms) } \\
\cline { 2 - 3 } & apply + hold & exhaust \\
\hline No leak & 388 & 195 \\
\hline With $\dot{q}_{l 1}$ & 687.5 & 320 \\
\hline With $\dot{q}_{l 2}$ & 486.6 & 210 \\
\hline With $\dot{q}_{l 1}$ and $\dot{q}_{l 2}$ & 1174.1 & 550 \\
\hline
\end{tabular}

Table 3. Output coordinating time

\begin{tabular}{c|c|c|c|c}
\hline \multirow{2}{*}{ component } & \multicolumn{4}{|c}{ Output coordinating time (ms) } \\
\cline { 2 - 5 } & No leak & $\dot{q}_{l 1}$ & $\dot{q}_{l 2}$ & $\dot{q}_{l 1}+\dot{q}_{l 2}$ \\
\hline EPV - RV & 33 & 195 & 33 & 195 \\
\hline RV - BC & 47 & 244 & 62 & 260 \\
\hline
\end{tabular}

The braking coordinating time refers to the reaction time of key brake units from the time the EPV is energized with electrical energy to each unit starting to have an output pressure. The brake response and output cordinating time are important indicators which should be adopted in the design and manufacturing of modern onboard and offboard fault discovery and extraction devices for train and other automobile systems where their requested actions need quick answers during usage. The different fault types are further classified using a binary coding system in relation to the response and cordinating time of the key braking unit (table 4). Where B: brake chamber, B-R: Brake chamber to relay valve: R: relay valve, R: Relay valve to Electrovalve, E-Electrovalve and E-C: Electrovalve to Compressor. NF: Fault Free State of the system.

Table 4. Fault code table

\section{Discussion}

\begin{tabular}{c|c|c|c|c|c|c}
\hline Fault & $\mathrm{a}_{3}$ & $\mathrm{a}_{2}$ & $\mathrm{a}_{1}$ & $\mathrm{a}_{0}$ & $\mathrm{t}_{\mathrm{r}}(\mathrm{s})$ & $\mathrm{S}$ \\
\hline $\mathrm{NF}$ & 0 & 0 & 0 & 0 & 0.8 & 0 \\
\hline $\mathrm{B}$ & 0 & 0 & 0 & 0 & 0.9 & $\mathrm{a}$ \\
\hline $\mathrm{B}-\mathrm{R}$ & 0 & 0 & 1 & 0 & 1.1 & $\mathrm{~b}$ \\
\hline $\mathrm{R}$ & 0 & 0 & 1 & 1 & 1.3 & $\mathrm{c}$ \\
\hline $\mathrm{R}-\mathrm{E}$ & 0 & 1 & 0 & 0 & 1.5 & $\mathrm{~d}$ \\
\hline $\mathrm{E}$ & 0 & 1 & 0 & 1 & 1.7 & $\mathrm{e}$ \\
\hline $\mathrm{E}-\mathrm{C}$ & 0 & 1 & 1 & 0 & 1.9 & $\mathrm{f}$ \\
\hline $\mathrm{W}$ & 0 & 1 & 1 & 1 & 2.3 & $\mathrm{~g}$ \\
\hline
\end{tabular}

For fault discovery and extraction, the neuro-fuzzy system involve, training and testing module to select $\mathrm{ANFIS}_{\mathrm{D}}$ and ANFIS $_{\mathrm{E}}$, effective training with confortable performance for validation using test patterns. The input quantities adopted are supply pressure $P_{S}=[0: 5]$ bar, i current $i_{e p v}=[0 ; 1] A$ and the leak effective area $S_{L i} C_{d L i}=[0: 74] \mathrm{mm}^{2}$. The piston velocity and response time are the two output figure 4-6.

Training parameters: supply pressure $P_{s}=[0: 4.5: 5]$ bar, input current $i_{\text {epv }}=[0: 0.375: 1] A$ and the leak effective area $S_{L i} C_{d L i}=[0: 74: 84] \mathrm{mm}^{2}$.

Testing parameters $P_{S}=[0: 4.8: 5]$ bar, input current $i_{e p v}=[0 ; 0.5: 1] A$ and the leak effective area $S_{L i} C_{d L i}=$ [0: 74: 92] $\mathrm{mm}^{2}$. Residuals $\left(r_{j}\right)$ are generated based on the inconsistence between the fault free and faulty model. $P_{L i}$ is the pressure in the presence of leaks, $\mathrm{j}=1,2 \ldots \mathrm{n}$.

$$
\begin{gathered}
\frac{d P_{L i}}{d t}=\frac{d P_{i}}{d t}-\frac{\dot{q}_{L i}}{d t} \\
r_{j}=\frac{P_{i}-P_{L i}}{P_{i}} \times 100 \%
\end{gathered}
$$

Figure 9-10 are extracts that valorize the quality of the $\mathrm{ANFIS}_{\mathrm{D}}$ design. The training and testing signals collected from 
high esteem features are learnt using a series of gaussian and generalized bell membership functions as in figure (8). They are blind in a fuzzified manner to form a Sugeno fuzzy fault detector with six input and one output. Moralised using two linguistic terms for each input; 64 fuzzy rules, 448 linear parameters; 42 nonlinear parameters; 535 training data pairs with considerable fuzzy operators (figure 9).

The input coordinates are the pressure response across the EPV, RV and BC respectively, with or without leaks induced in the pneumatic system. Fault discovery limit and their accuracies between actual and predicted are seen after many training and testing. Figure 10 is the structure of $\mathrm{ANFIS}_{\mathrm{D}}$. But it should be noted here that the differences gained from the respective fair and unfair signals on both cases are denoted as residuals, before fault discovery is carried out using ANFIS $_{\mathrm{D}}$ (table Table 3.4).

Figure 7 are typical examples of the trained and tested signal correlating the piston output velocity coordinating time and the inputs coordinates. Not all the input signals are shown in this section because of space limitation.

Table 3.5. Input identification table for the ANFIS $_{D}$

\begin{tabular}{l|l}
\hline \multicolumn{1}{c|}{ Reference } & \multicolumn{1}{c}{ Parametric identification } \\
\hline Input 1 & Plunger displacement of the Electropnuematic valve \\
\hline Input 2 & Pressure response of the Electropnuematic valve \\
\hline Input 3 & Plunger displacement of the relay valve \\
\hline Input 4 & Pressure response of the relay valve \\
\hline Input 5 & Piston displacement in brake chamber \\
\hline Input 6 & Pressure response of the brake chamber \\
\hline Output & Coordinating time of the piston \\
\hline
\end{tabular}
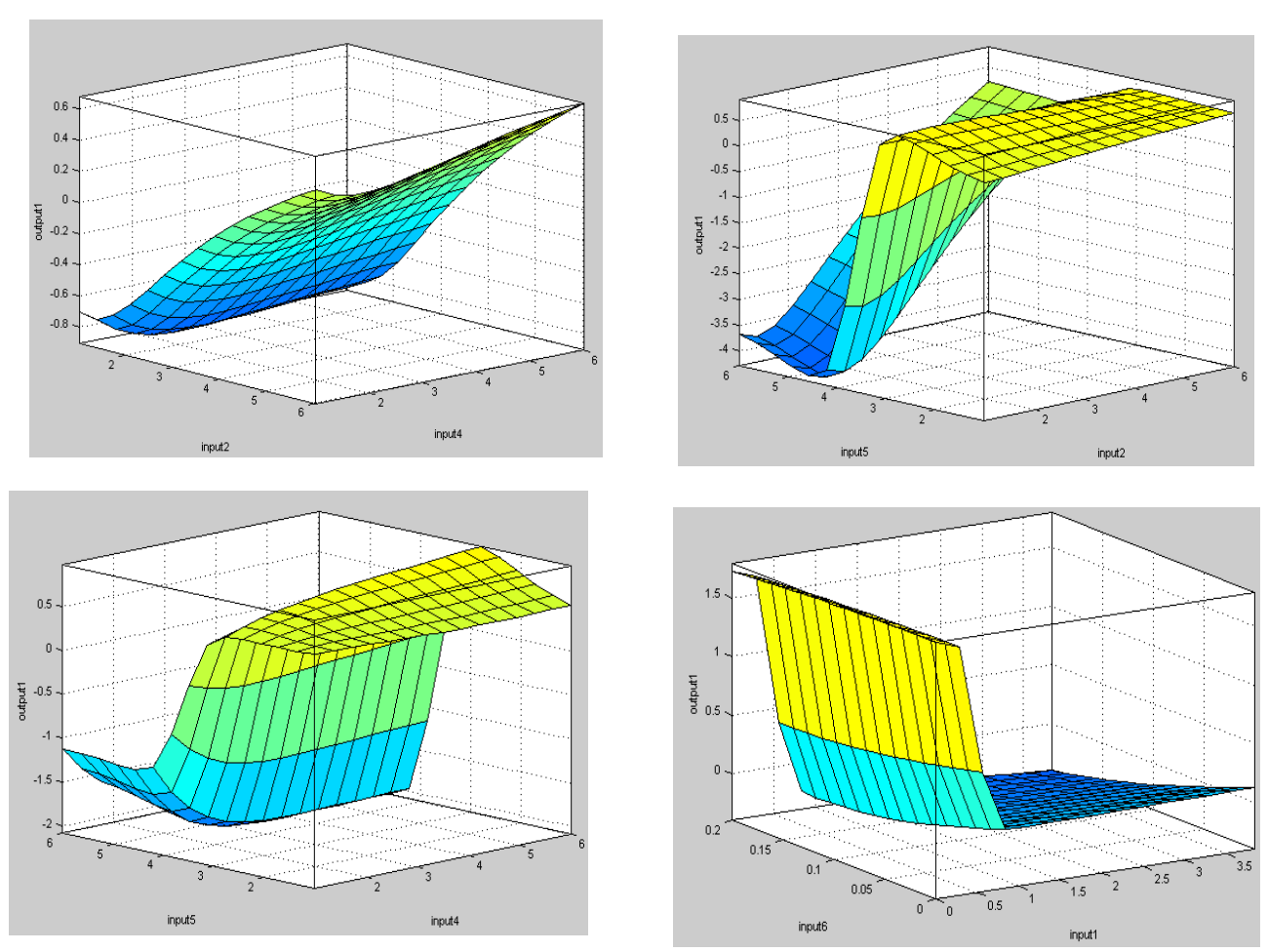

Figure 9. Attitude of the ANFIS input variables 

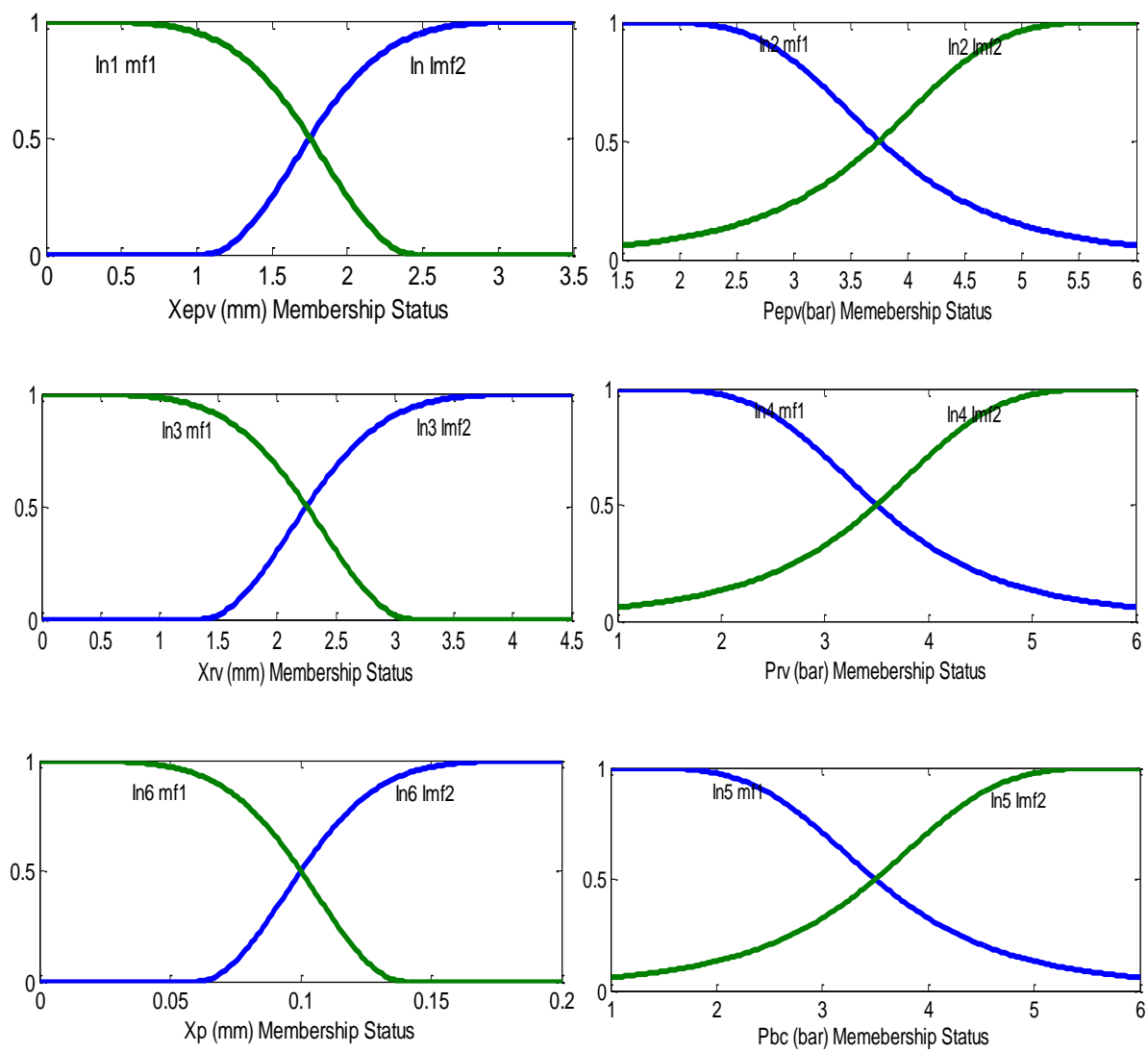

Figure 10. Input status for membership functions used for Fault discovery

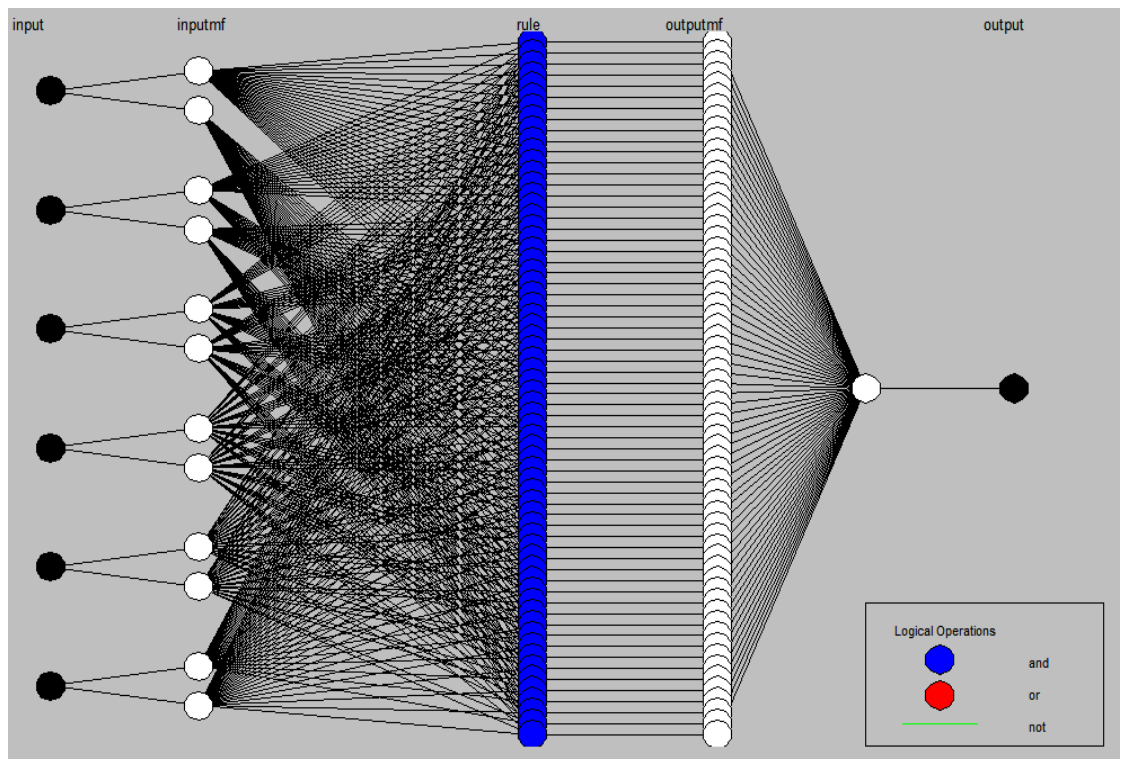

Figure 11. Structure of the neuro-fuzzy fault detector

To discover leaks issues which contribute to about $65 \%$ of train pneumatic brake failure modes, it is also necessary that the discovery units be user friendly or easy to be interpreted. For simplicity the output of the ANFIS $\mathrm{D}_{\mathrm{D}}$ shall have the number one $\left(\right.$ ANFIS $\left._{\text {Dout }}=1\right)$ for unfair mode and zero $\left(A N F I S_{\text {Dout }}=0\right)$ for good status of the case study (figure 47 ). The goodness of

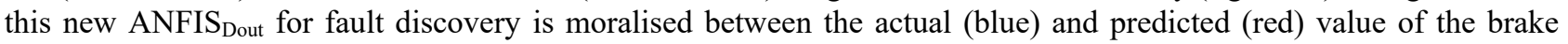
chamber piston motion. 

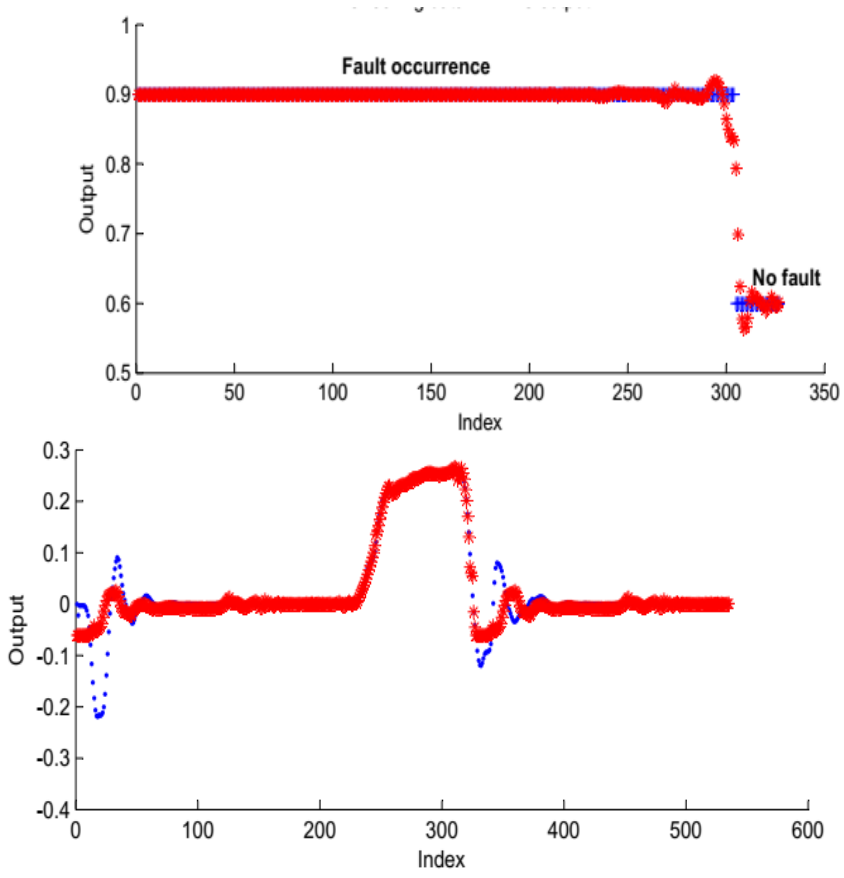

Figure 12 a). ANFIS output for fault detection b) Relation between actual and predicted value

The tracking of different unpleasant conditions heavily rely on quality of the extractors. To approve the hybrid model, the healthy and faulty state centered on developed residuals are respected during construction regarding same patterns as of the fault discovery system. To outstand ANFIS $_{\mathrm{E}}$, training and testing signals collected from high esteem features are being learnt using a series of gaussian and generalized bell member ship functions as in figure 11. These member ship functions are blind in a fuzzified manner to form a second Sugeno fuzzy fault extractor with six inputs and one output. Moralised using two and three linguistic terms for each input; 144 fuzzy rules, 448 linear parameters; 48 nonlinear parameters; 622 training data pairs with considerable fuzzy operators (figure 12). The input coordinates are the pressure response and flow rate across the EPV, $\mathrm{RV}$ and $\mathrm{BC}$ respectively, with and without leaks induced in the pneumatic system. Figure 12 denote the output of the fault extractor and their segregated interval of occurencies (no fault: 0; abcdefg corresponds to B, B-R, R, R-E, E, E-C, W).

Table 5 compares the output errors of the initiated ANFIS's for fault discovery and extraction using grid partition and subtractive clustering with different optimization techniques (hybrid or back propagation). The smallest error obtained from the combination of subtractive and hybrid techniques. Their combination is favorable in the development of quality ANFIS systems suitable for fault discovery and extraction modules for industrial or process plants.

Table 3.7. Input identification table for the $\mathrm{ANFIS}_{\mathrm{E}}$

\begin{tabular}{l|l}
\hline Reference & \multicolumn{1}{c}{ Parametric identification } \\
\hline Input 1 & Flow rate across the Electropnuematic valve \\
\hline Input 2 & Pressure response of the Electropnuematic valve \\
\hline Input 3 & Flow rate across the relay valve \\
\hline Input 4 & Pressure response of the relay valve \\
\hline Input 5 & Flow rate across the brake chamber \\
\hline Input 6 & Pressure response of the brake chamber \\
\hline Output & Coordinating time of the piston \\
\hline
\end{tabular}



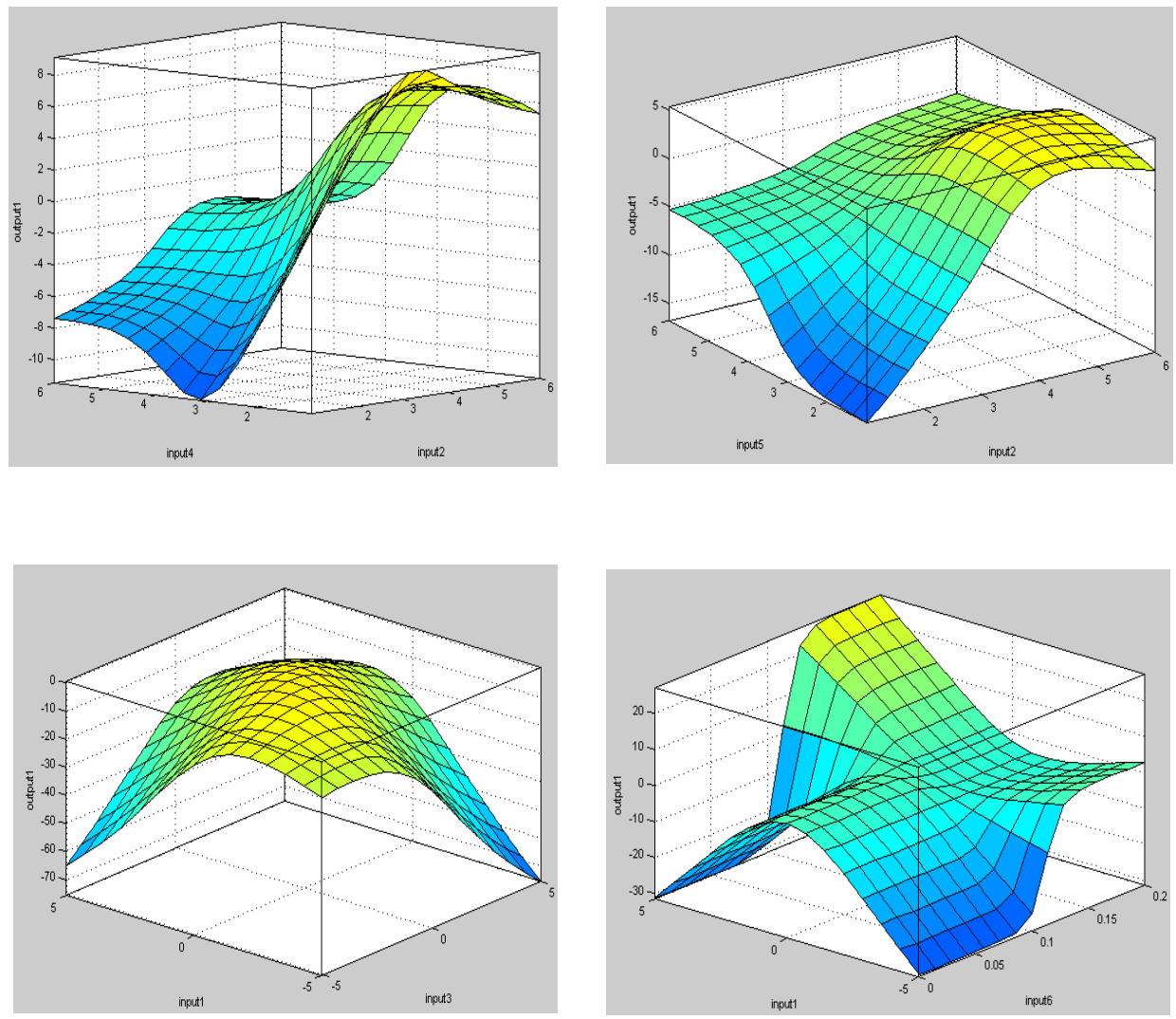

Figure 13. Attitude of the $\mathrm{ANFIS}_{\mathrm{E}}$ input variables
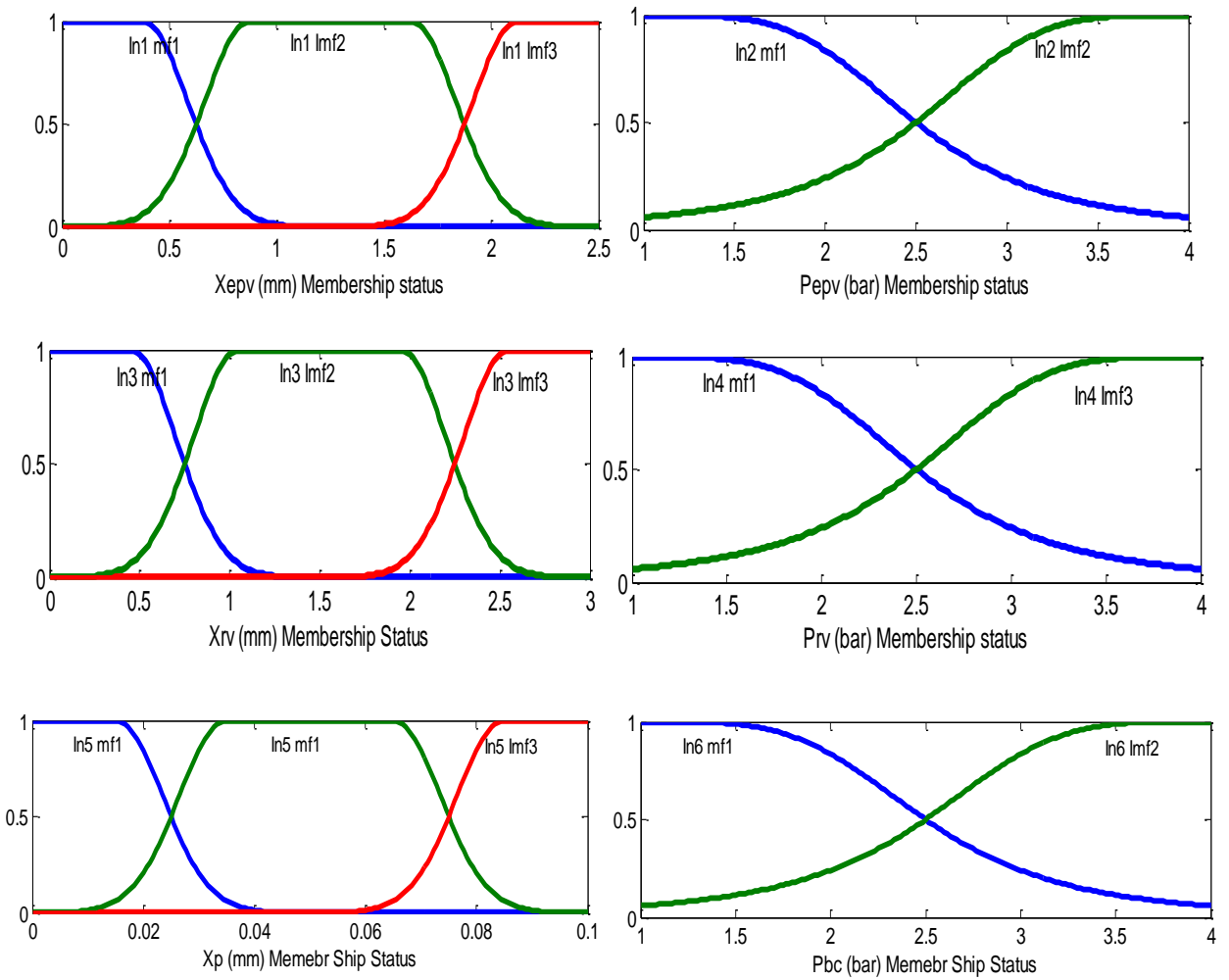

Figure 14. Input status for membership functions used for Fault extraction

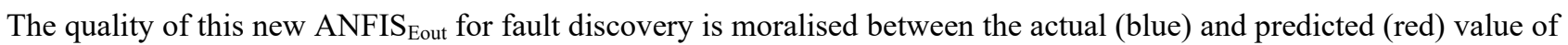
the brake chamber piston output coordinating time extracted in table 3.6. Each outputs relates to a class of defect components. The class I failure mode is considered here as the fault produced due to wear of the brake lining or disk 
mounted on the axle shaft. We consider this issue because when there is no contact between the disc and the lining material, no matter the response time of the pneumatic components the braking will not be realised during field operations of the train. Wear on train wheels and lining is a critical issue in the rolling stuck industry and must be address severely which is the objective of the next paper.

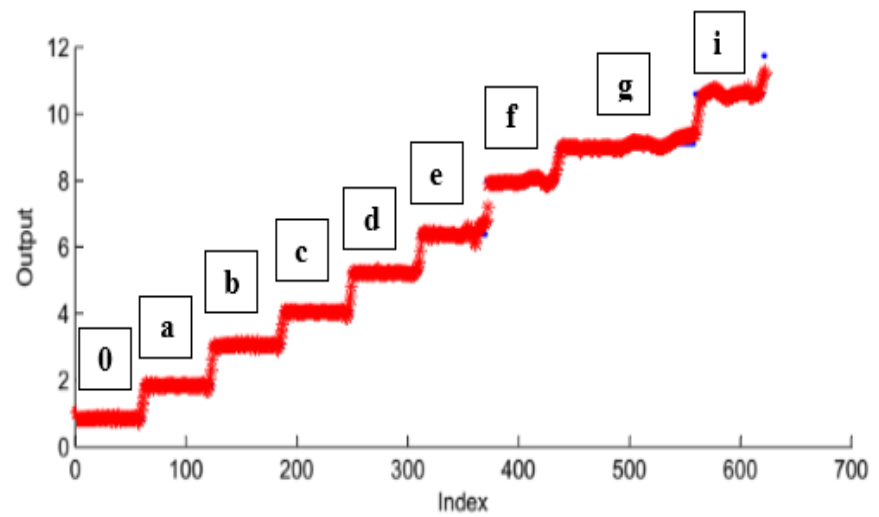

Figure 15. Output for $\mathrm{ANFIS}_{\mathrm{E}}$

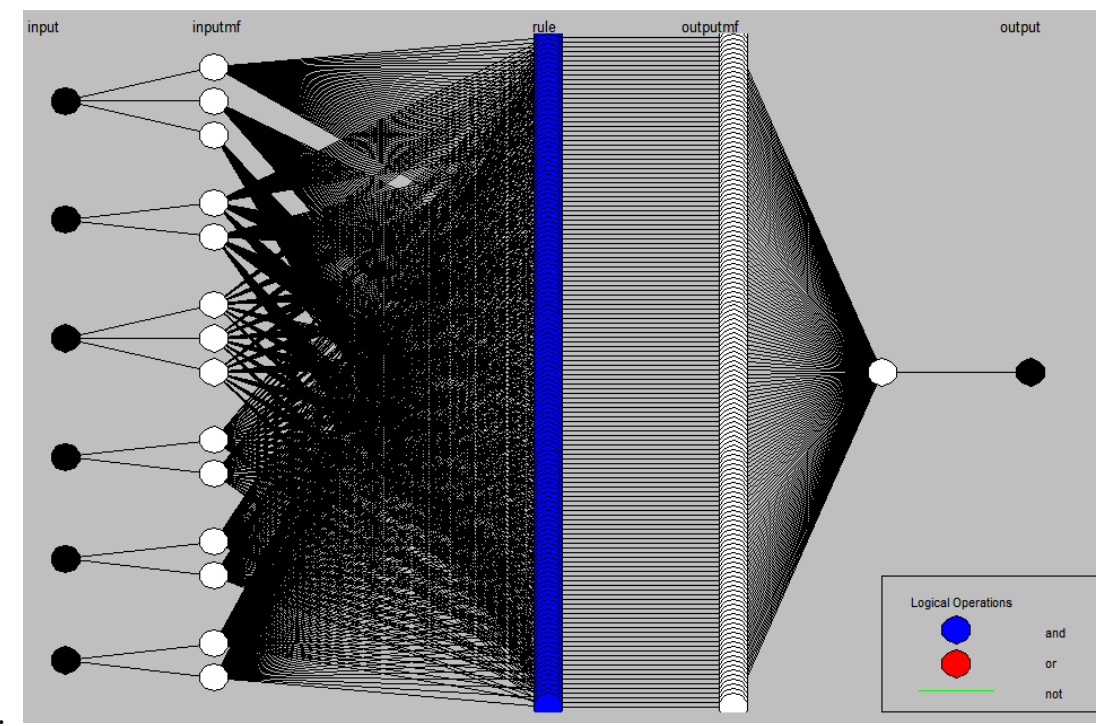

Figure 16. Structure of the neauro-fuzzy fault detector

Table 5. Output errors with different training and testing rate

\begin{tabular}{|c|c|c|c|c|}
\hline Method & FDE & Clustering technique & Optimisation. technique & $\%$ Error \\
\hline \multirow{8}{*}{ ANFIS } & \multirow{4}{*}{ Discovery } & \multirow{2}{*}{ Grid patition } & Hybrid & 3.15 \\
\hline & & & Back propagation & 4.83 \\
\hline & & \multirow{2}{*}{ Subtractive clustering } & Hybrid & 1.46 \\
\hline & & & Back propagation & 3.87 \\
\hline & \multirow{4}{*}{ Extractor } & \multirow{2}{*}{ Grid patition } & Hybrid & 10.79 \\
\hline & & & Back propagation & 15.93 \\
\hline & & \multirow{2}{*}{ Subtractive clustering } & Hybrid & 3.64 \\
\hline & & & Back propagation & 11.53 \\
\hline
\end{tabular}

Finally, this research work has discussed a systematic diagnostic process that can be applied on railway facilities or other rotating systems for the improvement of condition based maintenance activities. The use of ANFIS technique for real time detection and segregation of faults on a train pneumatic braking system has been case studied using analytical 
techniques. Simulated results show that, the initiated approach is robust and capable of detecting and locating fault size due to its high selectivity and sensitivity performance. To completely improve on a condition base maintenance action on train track systems, the future of this novel approach will investigate the notion of prognostic since the management of modern industrial processes relies on proactive (prognostics) measures before active (diagnostics) measures.

\section{References}

Adel, A. E., \& Takashi, H. (2009). Fault detection in transmission lines using ANFIS. IEEJ Transactions on Industry Applications.

Boseong, S., Soo-Ho, J., Hyunseok, O., \& Byeng, D. (2016). Solenoid Valve Diagnosis for Railway Braking Systems with Embedded Sensor Signals and Physical Interpretation. Annual Conference of the Prognostics and Health Management Society.

Demetgul, M., Tansel, I. N., \& Taskin, S. (2009). Fault diagnosis of pneumatic systems with artificial neural network algorithms. Expert Systems with Applications, 36, 10512-10519. Elsevier. https://doi.org/10.1016/j.eswa.2009.01.028

Hadroug, N., Hafaifa, A., Kouzou, A., \& Chaibet, S. (2016). Faults detection in gas turbine using hybrid adaptive network based fuzzy inference systems. Diagnostyka, 17(4), 3-17.

He, Q., Zha, Y., Zhang, R., Sun, Q., \& Liu, T. (2017). Reliability analysis for multi-state system based on triangular fuzzy variety subset bayesian networks. Maintenance and Reliability, 19(2), 152-165. https://doi.org/10.17531/ein.2017.2.2

Jegadeeshwaran, R., \& Sugumaran, V. (2015). Brake fault diagnosis using Clonal Selection Classification Algorithm (CSCA). Elservier, IJEST, 18, 14-23. https://doi.org/10.1016/j.jestch.2014.08.001

Jie, L., Li, Y. F., \& Enrico, Z. (2016). A Support Vector Method Framework for fault detection of the braking system in a high speed train. MSSP.

Lee, J., Fangji, W., Wenyu, Z., \& Mahsa, G. (2014). Prognostics and health management design for rotary machinery systems. MSSlP, 314-334. https://doi.org/10.1016/j.ymssp.2013.06.004

Lionel, B., \& Chen, L. (2011). High-speed train pneumatic braking system with wheel-slide protection device: A modelling application from system design to HIL testing. Modelica.

Lu, Y., Xu, B., \& Guo, B. (2015). Dynamic Modeling and Experimental Verification of Bus Pneumatic Brake System. Mechanical Engineering Journal, 9, 52-57. https://doi.org/10.2174/1874155X01509010052

Marcus, B., Herald, S., Thomas, W., \& Rolf, I. (2000). Model based detection of vehicle suspension system and hydraulic brake system. IFAC mechatronic system.

Muhammad, S., Cheol-Hong, K., \& Jong-Myon, K. (2017). A Hybrid Feature Model and Deep-Learning-Based Bearing Fault Diagnosis. Sensors.

Peng, X. M., \& Jin, X. N. (2018). Rail Suspension System Fault Detection using Deep Semi-Supervised Feature Extraction with One-class data. Annual Conference of the Prognostics and Health Management Society.

Shahab, M., \& Moavenian, (2012). Fault detection and isolation of a vehicle drive line. IJAE.

Shankar, R. C. S. A. (2006). Diagnostic System for Air Brakes in Commercial Vehicles. Ph.D thesis, IEEE on Intelligent Transportation Systems.

Srivatsan, R. (2008). A mathematical model for air brake systems in the presence of leaks. Thesis.

Tse, S. A., Wolfgang, N., Bonaventure, D., \& Bertin, S. F. (2014). Modeling of Train Track Vibration for Maintenance Purposes. European Scientific Journal.

Vasile, P., Ron, J. P., Faisel, J. U., \& Joseba, Q. S. D. (2002). Fault diagnosis of an industrial gas turbine using neuro-fuzzy methods. IFAC Congress, Barcelona 


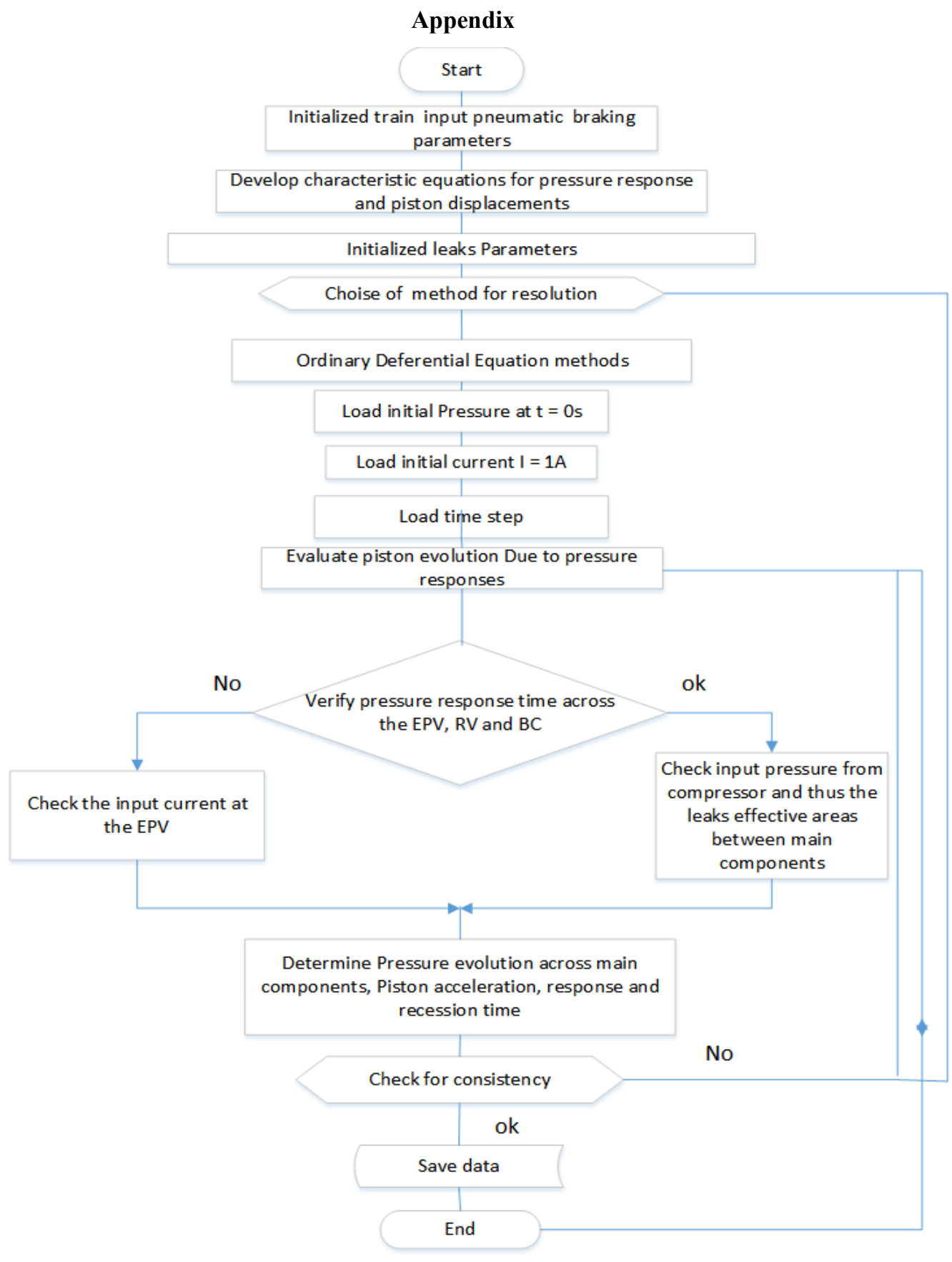

\section{Copyrights}

Copyright for this article is retained by the author(s), with first publication rights granted to the journal.

This is an open-access article distributed under the terms and conditions of the Creative Commons Attribution license which permits unrestricted use, distribution, and reproduction in any medium, provided the original work is properly cited. 